\title{
Phase selection during pulsed laser annealing of manganese
}

D. M. Follstaedt and P. S. Peercy

Sandia National Laboratories, Albuquerque, New Mexico 87185

\author{
J. H. Perepezko \\ Department of Metallurgical and Mineral Engineering, University of Wisconsin-Madison, Madison, \\ Wisconsin 53700
}

(Received 18 November 1985; accepted for publication 4 December 1985)

\begin{abstract}
Pulsed (25 ns) laser-induced heating of the $\alpha$ phase of $\mathrm{Mn}$ is found to be sufficiently rapid to bypass solid-state transformation to the high-temperature $\beta, \gamma$, and $\delta$ allotropes and thus produce melts that are calculated to be undercooled by $\sim 120 \mathrm{~K}$ with respect to the equilibrium melting temperature of the $\delta$ phase. Nucleation of the $\gamma$ phase in this highly undercooled melt is observed for sufficiently long melt durations. The experiments thus demonstrate that pulsed laser-induced melting of metals with allotropes permits the study of nucleation and growth in highly undercooled melts with calculable temperatures.
\end{abstract}

Rapid solidification treatments have been used in numerous studies to produce novel microstructures, including metastable phases and amorphous structures.' Rapid surface melting by pulsed laser irradiation permits quantitative assessment of kinetic constraints that influence the structure modification. $^{2-5}$ However, the phases which result from pulsed surface melting are influenced by the underlying crystalline substrate and the outermost liquid surface (which may be coated with an oxide film), and thus most structural modifications are supersaturated solid solutions of the substrate phase or thin amorphous layers. These structures result more from competitive crystal growth conditions $^{2}$ than from nucleation of new crystalline phases, which has only been examined to a limited extent. ${ }^{6}$

To exploit the well-controlled conditions available with pulsed surface melting for studies of nucleation within the melt, we have examined laser-induced surface melting of Mn. By rapidly melting a low-temperature phase of an allotropic metal, a liquid which is significantly undercooled with respect to the equilibrium melting point of the highest temperature phase can be achieved. Manganese has four allotropic phases with well-defined thermodynamic properties summarized in Table I. ${ }^{7,8}$ The phases quenched in after surface melting reflect the degree of undercooling of the melt and the nucleation and growth kinetics of the possible phases in the melt. In the experiments reported in this letter, undercoolings calculated to be $122 \mathrm{~K}$ were achieved by melting the low-temperature $\alpha$ phase. This strategy is applicable to other metals with allotropes as well.

The temperature dependence of the free-energy differences from the liquid, $\Delta G_{m}^{i}=G_{i}-G_{L}$ (where $i=\alpha, \beta, \gamma$, or $\delta$ ), is presented in Fig. 1 . The data for the stable equilibri$\mathrm{um}^{7}$ were used to determine the metastable transition temperatures. For example, the melting point $T_{m}^{\gamma}$ for $\gamma$ lies between the melting point for $\delta, T_{m}^{\delta}$, and the $\delta / \gamma$ allotropic transition temperature, $T_{\delta / \gamma}$. Neglecting the heat capacity difference between liquid, $\delta$, and $\gamma, T_{m}^{\gamma}$ is given by ${ }^{9}$

$$
T_{m}^{\gamma}=\frac{\Delta S_{\delta / \gamma} T_{\delta / \gamma}+\Delta S_{m}^{\delta} T_{m}^{\delta}}{\Delta S_{\delta / \gamma}+\Delta S_{m}^{\delta}},
$$

where $\Delta S_{\delta / \gamma}$ is the entropy change for the $\delta / \gamma$ transition and $\Delta S_{m}^{\delta}$ is the melting entropy for $\delta$. Measurements on several pure metals ${ }^{10}$ show that neglecting the heat capacity differences involves an error of less than 5\%; however, extension of the free-energy plot in Fig. 1 to lower temperatures than shown requires heat capacity and magnetic entropy corrections. " The same approach also allows evaluation of the molar free-energy differences between the solid phases, expressed as $\Delta G_{i / j}=\Delta S_{i / j} \Delta T$, with $\Delta T=T_{i / j}-T$ where $T_{i / j}$ is the equilibrium transformation temperature. Metastable transformation temperatures between the allotropes can then also be calculated, e.g., $T_{\alpha / \delta}$. Calculated transition temperatures and expressions for $\Delta G_{m}{ }_{m}$ are listed in Table I.

Samples of $\alpha$-phase Mn ( $99.99 \%$ purity) were metallographically and electrochemically polished to obtain a flat surface. Irradiation was provided by a $Q$-switched ruby laser (25-ns full width at half-maximum) through a quartz homogenizer ${ }^{12}$ to assure beam uniformity $(\leqslant \pm 5 \%)$. Realtime measurement of the reflectance during irradiation was obtained with an argon ion probe laser $(488 \mathrm{~nm})$ incident on the sample surface at glancing angle. The transient reflectance measurements and subsequent changes in the surface appearance were used to determine when melting occurred. Samples for transmission electron microscopy (TEM) were prepared by back thinning using a jet electropolishing with an acid solution $\left(500 \mathrm{ml} \mathrm{H}_{2} \mathrm{O}+1.25 \mathrm{ml} \mathrm{H}_{3} \mathrm{PO}_{4}\right.$ at $5^{\circ} \mathrm{C}$ ) to expose the irradiated near surface for observation of a depth of $\sim 0.1 \mu \mathrm{m}$.

After irradiation of an $\alpha$-phase sample at an incident energy density of $0.77 \mathrm{~J} / \mathrm{cm}^{2}$, the $\alpha$ phase was retained in the near surface region of the substrate, as shown by the electron diffraction pattern in Fig. 2(a). This energy density was the lowest observed to produce a change in surface reflectivity after treatment, which implies that it slightly exceeds the melt threshold. At $0.88 \mathrm{~J} / \mathrm{cm}^{2}$, which was clearly above the melt threshold, the electron diffraction pattern from the melted layers was again predominantly $\alpha$ phase, although some weak diffraction rings which may be due to $\gamma$ phase were observed in isolated regions of the sample. At $1.16 \mathrm{~J} /$ $\mathrm{cm}^{2}$ there was clear evidence for the formation of $\gamma$ phase in the melted layer as indicated by the $(110\rangle$ fcc pattern shown in Fig. 2(b). Additional $\gamma$-phase diffraction patterns similar to that of Fig. 2(b), some with $(112\rangle)$ orientations, were also obtained at $1.48 \mathrm{~J} / \mathrm{cm}^{2}$. To our knowledge, this is the first 
TABLE I. Thermodynamic characteristics of Mn allotropes.

\begin{tabular}{|c|c|c|c|c|c|}
\hline $\begin{array}{l}\text { Allotrope } \\
\text { (structure) }\end{array}$ & $\begin{array}{c}\text { Stability } \\
\text { range } \\
\text { (K) }\end{array}$ & $\begin{array}{c}T_{m} \\
(\mathbf{K})\end{array}$ & $\begin{array}{l}T_{i / \alpha} \\
(\mathbf{K})\end{array}$ & $\begin{array}{c}\Delta G_{m}^{\prime} \\
(\mathrm{J} / \mathrm{mol})\end{array}$ & $\begin{array}{c}V_{m} \\
\left(\mathrm{~m}^{3} / \mathrm{mol}\right) \times 10^{\circ}\end{array}$ \\
\hline$\alpha(\mathrm{A} 12)$ & $0-980$ & $1395^{a}$ & & $13.09(1395-T)$ & $7.35^{\mathrm{c}}$ \\
\hline$B(\mathbf{A} \mid \mathbf{3})$ & $980-1360$ & $1481^{\mathrm{a}}$ & 980 & $10.83(1481-T)$ & $8.32^{c}$ \\
\hline$\gamma(\mathrm{A} 1)$ & $1360-1410$ & $1501^{\mathrm{a}}$ & $1137^{6}$ & $9.28(1501-T)$ & $8.67^{d}$ \\
\hline$\delta(\mathrm{A} 2)$ & $1410-1517$ & 1517 & $1209^{b}$ & $7.94(1517-T)$ & $8.79^{e}$ \\
\hline
\end{tabular}

"Calculated metastable melting point.

${ }^{b}$ Calculated metastable transition temperature.

At $300 \mathrm{~K}$.

dAt $1373 \mathrm{~K}$.

'At $1398 \mathrm{~K}$.

time that the $\gamma$ phase has been quenched to room temperature in pure Mn.

Most diffraction patterns from samples irradiated at the two higher energies consisted of $\gamma$-phase and $\alpha$-phase Mn; both ring and spot diffraction patterns were observed from areas several microns in diameter. Diffuse oxide rings and relatively sharp rings indexing to $\mathrm{MnO}$ were also observed. The relative intensities of the $\gamma$ and $\alpha$ reflections varied with sample position and occasionally evidence was detected for twinning in the $\gamma$ phase. The lattice constant for the fcc $\gamma$ phase was observed to be $a_{0}=0.383 \pm 0.013 \mathrm{~nm}$, which is consistent with previous measurements. ${ }^{13}$ Based on dark field microscopy and on sample dimensions giving single orientation diffraction patterns, we estimate grain sizes of the $\gamma$ phase of order of $1 \mu \mathrm{m}$. The $\beta$ and $\delta$ phases of Mn were not observed after any treatments.

If the heating is sufficiently rapid to suppress solid-state transformations of $\alpha$-Mn to any of the other allotropes, melting occurs when the laser heats the near surface to $T_{m}^{\alpha}$ $=1395 \mathrm{~K}$. The melt front then propagates into the solid until the temperature across the molten layer cools to the melting point of the substrate; regrowth of $\alpha-\mathrm{Mn}$ into the liquid is then permitted. Upon reaching this metastable $\alpha$ liquid equilibrium, the melt zone is under cooled by $122 \mathrm{~K}$

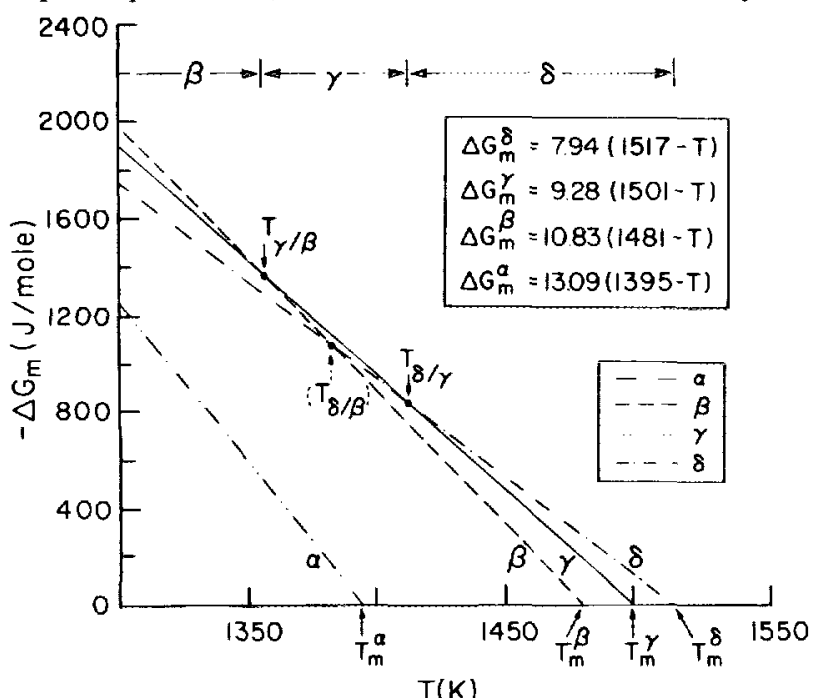

FIG. 1. Free-energy differences relative to liquid $\mathrm{Mn}$ for each of the four allotropic phases of $\mathbf{M n}$, as functions of temperature, calculated as described in the text. Melting points $\left(T_{m}^{\prime}\right)$ and solid phase transformation temperatures $\left(T_{i / j}\right)$ are indicated. The equilibrium solid phase are indicated at the top. with respect to the stable $\delta$ - $L$ equilibrium. The liquid will be further undercooled to somewhat below $T_{m}^{\alpha}$ in order to regrow the $\alpha$-phase solid at velocities which are expected to be in the meters/second regime.

Several experimental observations indicate that allotropic transformations do not occur with laser treatment of the $\alpha$ phase. First, when $\beta$ is formed during furnace annealing, we find that it can be retained to room temperature by a modest quench rate $\left(\sim 10^{3}-10^{4} \mathrm{~K} / \mathrm{s}\right)$. Thus, if $\beta$ had formed during any of the irradiations, it would have been retained during the subsequent rapid quench (calculated to be $\sim 10^{10}$ $\mathrm{K} / \mathrm{s}$ ). Second, the retention of $\gamma$ following its nucleation from the liquid establishes that an $\alpha \rightarrow \gamma$ reaction in the 0.77 $\mathrm{J} / \mathrm{cm}^{2}$ sample would have been observed had it occurred. Finally, if $\alpha$ had transformed to $\delta$, then the $\gamma$ phase observed with $1.16 \mathrm{~J} / \mathrm{cm}^{2}$ would have to form by solid phase transformation, which we argue below to be very unlikely.

For solid-state reactions between pure metal phases the rate of incoherent interface propagation can be described by $^{14}$

$$
v=v_{0}\left[1-\exp \left(-\Delta G_{i / j} / R T\right)\right],
$$

where $v_{0}$ is a product of terms involving jump frequency of atoms at an interface, the jump distance and growth site fraction, and can be estimated by $D_{b} / a_{0}$, where $D_{b}$ is a boundary diffusivity and $a_{0}$ is the atomic spacing. For $\mathrm{Mn}$, limited diffusion measurements ${ }^{15}$ suggest $v_{0} \sim 10-100 \mathrm{~cm} / \mathrm{s}$. Estimates of the maximum transformation velocities based on an evaluation of Eq. (2) at the melting point of each phase give values of $\sim 10^{-1}-1 \mathrm{~cm} / \mathrm{s}$. Since the system spends $<10^{-6} \mathrm{~s}$ at elevated temperatures, a negligible amount of solid-state reaction (either growth or decomposition) is expected during pulsed laser heating and subsequent cooling. Thus both observations and calculated kinetics indicate that transformation to other possible allotropes does not occur before the onset of melting at $T_{m}^{\alpha}=1395 \mathrm{~K}$. Furthermore, the $\sim 1-\mu \mathrm{m}$ grains of $\gamma$ require growth rates in the meters/ second regime, which are only possible by growth into the liquid phase.

Several features of the $\gamma$-phase formation are notable. Since the melt time increases with incident energy density, the obvious presence of the $\gamma$ phase of 1.16 and $1.48 \mathrm{~J} / \mathrm{cm}^{2}$, and its absence at $0.77 \mathrm{~J} / \mathrm{cm}^{2}$, show that its formation is related to the duration of the melt. With this interpretation these results can be used to estimate nucleation kinetics of $\gamma$ in the undercooled melt. To obtain an upper limit on the time 

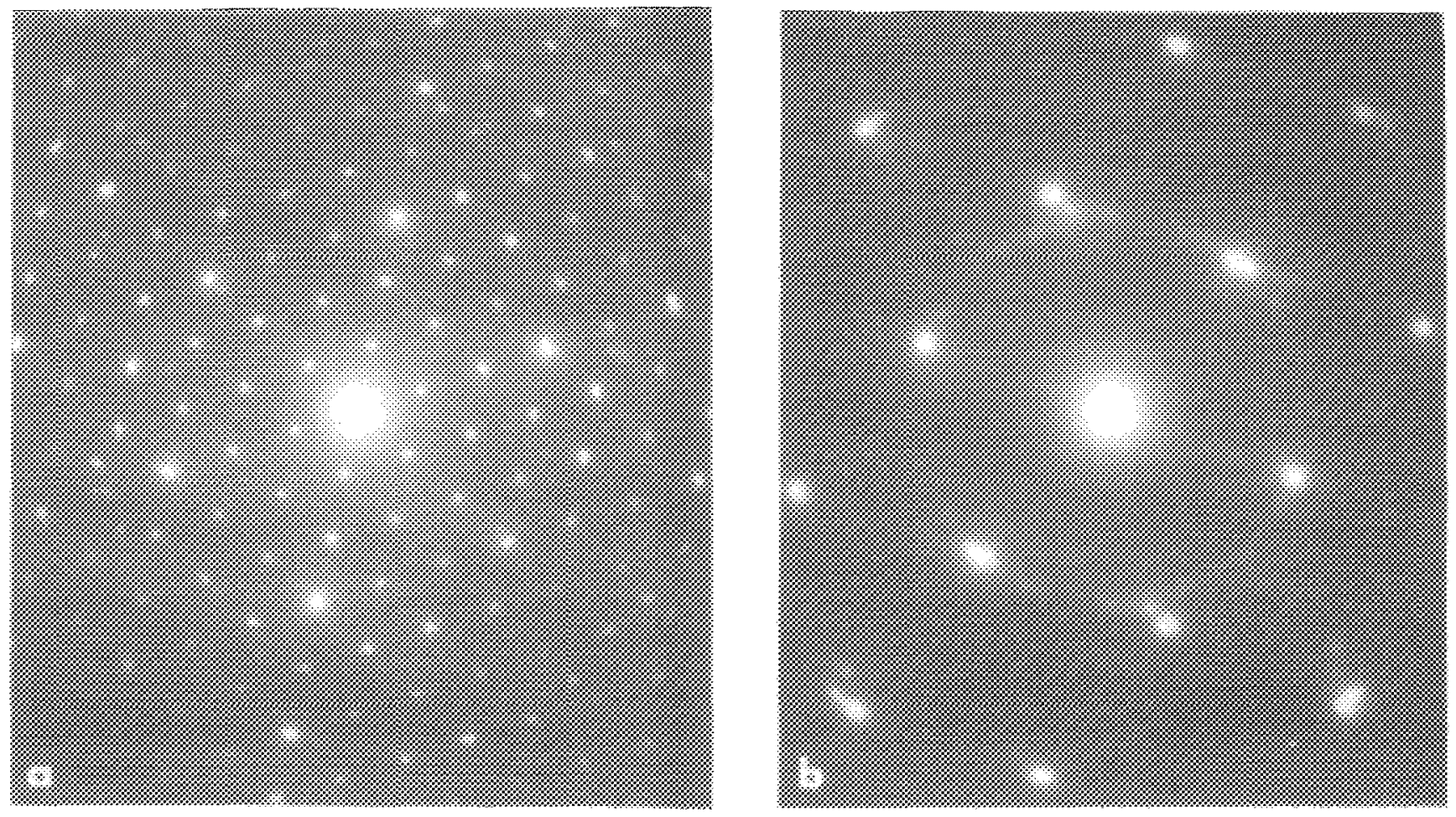

FIG. 2. Electron diffraction patterns taken with TEM at $120 \mathrm{kV}$ from laser-irradiated $\alpha-\mathrm{Mn}$. (a) (111) zone pattern of $\alpha$-Mn obtained after $0.77 \mathrm{~J} / \mathrm{cm}^{2}, 25-\mathrm{ns}$ laser pulse. (b) (110) zone pattern of $\gamma-\mathrm{Mn}$ obtained after $1.16 \mathrm{~J} / \mathrm{cm}^{2}, 25$-ns laser pulse, with a superimposed (111) ring at $d=0.22 \mathrm{~nm}$ from misoriented $\gamma$ $\mathrm{Mn}$.

needed for nucleation, numerical heat flow calculations were performed for melting and resolidification of $\alpha-\mathrm{Mn}$. The calculation used the reflectivity $(0.8)$ obtained by fitting the observed melt threshold $\left(\sim 0.8 \mathrm{~J} / \mathrm{cm}^{2}\right)$ for the samples used to obtain the data in Fig. 2. The major uncertainty in applying these calculations to the experiment results from the difficulty in preparing reproducible, high reflectivity samples. For $1.16 \mathrm{~J} / \mathrm{cm}^{2}$ we obtain a melt duration of $45 \mathrm{~ns}$, which places an upper limit on the nucleation time of fcc $\gamma$-Mn. This time is comparable to the measured nucleation time of $15 \pm 10$ ns for cubic AlSb in molten $\mathrm{Al}^{5}$

Nucleation of $\gamma$ requires the liquid to be undercooled below its melting point $T_{m}^{\gamma}=1501 \mathrm{~K}(\Delta T>16 \mathrm{~K})$; however, nucleation may have occurred at temperatures down to or below $T_{m}^{a}=1395 \mathrm{~K}(\Delta T \sim 122 \mathrm{~K})$. The dominant phase to nucleate is determined to a large extent by the lowest values for the activation barrier for nucleation, ${ }^{9}$ $\Delta G^{*}=K \sigma^{3}\left(\Delta G_{m} / V_{m}\right)^{2}$, where $K$ is related to the nucleus geometry and possible heterogeneous nucleant potency, $\sigma$ is the liquid-solid interface energy and $V_{m}$ is the molar volume. In terms of free energy, the phase with the largest $\left(\Delta G_{m} / V_{m}\right)$ value is favored. The use of temperature corrected $V_{m}$ values does not significantly change the temperature range favoring $\gamma$ from that shown in Fig. 1 (1410-1360 $\mathrm{K})$. If cooling into this range is needed for $\gamma$ nucleation, then the undercooling will exceed $117 \mathrm{~K}$, which can be achieved with pulse melted $\alpha-\mathrm{Mn}$. Alternatively the nucleation of $\gamma$ in preference to $\delta$ and $\beta$ may be due to the $K \sigma^{3}$ factor in $\Delta G *$.

In summary, a procedure has been developed for generating calculable liquid undercoolings by rapid surface melting of a low-temperature allotropic phase of a metal. The method was demonstrated for $\mathrm{Mn}$, where undercoolings of
$122 \mathrm{~K}$ were achieved by melting the $\alpha$ phase. This technique can be used to study the nucleation of other crystalline phases in the undercooled melt, as was shown here for $\gamma-\mathrm{Mn}$.

We thank A. Van Donsel and M. Moran for skillful assistance with sample preparation. This work was performed at Sandia National Laboratories supported by the $U$. S. Department of Energy under contract No. DE-AC04$76 \mathrm{DP} 00789$.

'See, e.g., Proceedings of the 4th International Conference on Rapidly Quenched Metals, edited by T. Matsumato and K. Suzuki (Japan Institute of Metals, Sendai, 1982).

${ }^{2}$ Michael O. Thompson, J. W. Mayer, A. G. Cullis, H. C. Weber, N. G. Chew, J. M. Poate, and D. C. Jacobson, Phys. Rev. Lett. 50, 896 (1983). ${ }^{3}$ Michael O. Thompson, G. J. Galvin, J. W. Mayer, P. S. Peercy, J. M. Poate, D. C. Jacobson, A. G. Cullis, and N. G. Chew, Phys. Rev. Lett. 52, 2360 (1984).

${ }^{4}$ P. S. Peercy, Michael O. Thompson, J. Y. Tsao, and M. J. Aziz, Appl. Phys. Lett. 47, 244 (1985).

${ }^{5}$ D. M. Follstaedt, S. T. Picraux, P. S. Peercy, J. A. Knapp, and W. R. Wampler, Mater. Res. Soc. Symp. Proc. 28, 273 (1984).

${ }^{6}$ M. Laridjani, P. Ramachandrarao, and R. W. Cohn, J. Mater. Sci. 7, 627 (1972).

${ }^{7}$ R. Hultgren, P. D. Desai, D. T. Hawkins, M. Gleiser, K. K. Kelley, and D. D. Wagman, Selected Values of the Thermodynamic Properties of the Elements (ASM, Metals Park, Ohio, 1973), p. 301.

${ }^{\mathrm{z}} \mathrm{W}$. B. Pearson, Handbook of Lattice Spacings and Structures of Metals and Alloys (Pergamon, Oxford, 1958), Vol. I, p. 734.

${ }^{9}$ J. H. Perepezko and W. J. Boettinger, Mater. Res. Soc. Symp. Proc. 19, 223 (1983).

${ }^{10}$ J. H. Perepezko and J. S. Paik, J. Non-Cryst. Solids 61, 113 (1984).

${ }^{11}$ R. J. Weiss and K. J. Tauer, J. Phys. Chem. Solids 4, 135 (1958).

${ }^{12}$ A. G. Cullis, N. C. Webber, and P. Bailey, J. Phys. E 12, 688 (1979).

${ }^{13}$ Z. S. Basinski and J. W. Christian, Proc. R. Soc. London A 223, 554 (1954).

${ }^{14} \mathrm{~J}$. W. Christian, The Theory of Transformations in Metals and Alloys (Pergamon, Oxford, 1965).

${ }^{15}$ J. Askill, Phys. Status Solidi K 33, 105 (1969). 